\title{
Índice del Número 12
}

\section{Páginas Preliminares}

Presentación general del número

Pág. 1-2

Graciela Tonon

Reconocimiento a los evaluadores del número 12

Pág. 3

Graciela Tonon

\section{Sección Artículos}

Una discusión sobre el rol de las Organizaciones Internacionales en la teoría de las Relaciones Internacionales

Pág. 4-21

Juan Facundo Carcedo

Igualdad de género, educación y trabajo: aproximación hacia la situación de Chile, Cuba y Finlandia

Iskra Pavez Soto, Carmen Alfaro y Laura Ochoa

\section{Sección Ensayos}

La internacionalización de la Educación Superior. Análisis del caso

Pág. 45-61

Proyecto Alfa Tuning América Latina

María Juliana Laurito y Denise Benatuil

Estereotipos de género transmitidos a los niños y niñas en la familia postpatriarcal

Alicia Noemi Bonelli

Pensar las prácticas de los trabajadores sociales en las escuelas desde la construcción adultocéntrica de la juventud. Una lectura posible desde la mirada de Foucault

Tatiana Leonor Lescano

Maldivas y el delicado equilibrio entre India y China

Matías Iglesias

Pág. 22-44

Pág. 62-85

Pág. 86-105

\section{Sección Política Internacional}

Introducción a la Sección Política Internacional

Pág. 122-125

Lía Rodríguez de la Vega

La cultura y el poder blando en las relaciones bilaterales: el caso de Argentina e India.

Pág. 126-130

Verónica Flores y Maya Alvisa Barroso

De la fundación de un país al muro fronterizo: una perspectiva social e histórica de la migración en Estados Unidos de Norteamérica

Pág. 131-137 Pablo Alejandro Berri 


\section{Sección Aportes de Estudiantes}

El Programa de Trabajo Autogestionado como respuesta estatal al fenómeno de las Empresas Recuperadas

Pág. 138-142 Solange Anahí Miner

Relación entre Movimientos Sociales y Estado en los Bachilleratos Populares

Juan Uriel Idalgo

\section{Sección Reseña y Rescate de Libros}

Introducción a la Sección Reseña y Rescate de Libros

Pág. 148

Daniel Del Percio

Ciudadanía y calidad de vida: Debates, retos y experiencias en torno al desarrollo social en México y América Latina María Mercedes Solé

Comunicación y poder: dos elementos inseparables

Pág. 143-147

Carmina C. Ortega Moreno 